\title{
Sequential Production of D-xylonate and Ethanol from Non-Detoxified Corncob at Low-pH by Pichia kudriavzevii via a Two-Stage Fermentation Strategy
}

\author{
Hao Ji ${ }^{1, *,+}$,, $\mathrm{Ke} \mathrm{Xu}^{1,+}{ }^{,}$Xiameng Dong ${ }^{2}$, Da Sun ${ }^{1}$ and Libo Jin $^{1}$ \\ 1 Institute of Life Sciences \& Engineering Laboratory of Zhejiang Province for Pharmaceutical Development of \\ Growth Factors, Wenzhou University, Wenzhou 325035, China; 20160226@wzu.edu.cn (K.X.); \\ sunday@wzu.edu.cn (D.S.); 20160121@wzu.edu.cn (L.J.) \\ 2 Department of Agriculture and Biotechnology, Wenzhou Vocational College of Science and Technology, \\ Wenzhou 325006, China; dongxiameng@wzvcst.edu.cn \\ * Correspondence: 20180031@wzu.edu.cn \\ + These authors contributed equally to this work.
}

Citation: Ji, H.; Xu, K.; Dong, X.; Sun, D.; Jin, L. Sequential Production of D-xylonate and Ethanol from Non-Detoxified Corncob at Low-pH by Pichia kudriavzevii via a Two-Stage Fermentation Strategy. J. Fungi 2021, 7, 1038. https://doi.org/10.3390/ jof7121038

Academic Editor: Laurent Dufossé

Received: 14 November 2021

Accepted: 1 December 2021

Published: 3 December 2021

Publisher's Note: MDPI stays neutral with regard to jurisdictional claims in published maps and institutional affiliations.

Copyright: (c) 2021 by the authors. Licensee MDPI, Basel, Switzerland. This article is an open access article distributed under the terms and conditions of the Creative Commons Attribution (CC BY) license (https:/ / creativecommons.org/licenses/by/ $4.0 /)$.

\begin{abstract}
Improving the comprehensive utilization of sugars in lignocellulosic biomass is a major challenge for enhancing the economic viability of lignocellulose biorefinement. A robust yeast Pichia kudriavzevii N-X showed excellent performance in ethanol production under high temperature and low $\mathrm{pH}$ conditions and was engineered for D-xylonate production without xylitol generation. The recombinant strain $P$. kudriavzevii N-X/S1 was employed for sequential production of D-xylonate and ethanol from D-xylose, feeding on D-glucose without $\mathrm{pH}$ control in a two-stage strategy of aerobic and shifting micro-aerobic fermentation. Acid-pretreated corncob without detoxification and filtration was used for D-xylonate production, then simultaneous saccharification and ethanol fermentation was performed with cellulase added at $\mathrm{pH} 4.0$ and at $40^{\circ} \mathrm{C}$. By this strategy, $33.5 \mathrm{~g} / \mathrm{L}$ D-xylonate and $20.8 \mathrm{~g} / \mathrm{L}$ ethanol were produced at yields of $1.10 \mathrm{~g} / \mathrm{g}$ D-xylose and $84.3 \%$ of theoretical value, respectively. We propose a promising approach for the sequential production of D-xylonate and ethanol from non-detoxified corncob using a single microorganism.
\end{abstract}

Keywords: ethanol; D-xylonate; Pichia kudriavzevii; sequential production; non-detoxified corncob

\section{Introduction}

Lignocellulosic biomass is a promising feedstock for the production of second-generation ethanol and biochemicals owing to its ready availability, economic efficiency and sustainability. D-glucose, abundantly present in lignocellulosic biomass, can be efficiently converted to ethanol using traditional Saccharomyces cerevisiae. D-xylose, the second most abundant sugar in lignocellulosic biomass, cannot be naturally utilized by $S$. cerevisiae. To improve the economic viability of the lignocellulosic ethanol industry, numerous genetic modifications have been performed to improve the xylose fermentation of $S$. cerevisiae in recent years [1]. In addition to converting D-xylose into ethanol, an alternative way to improve the lignocellulose-based bioeconomy is to convert D-xylose into other value-added chemicals [2].

Besides being reduced to xylitol, D-xylose can also be oxidized to D-xylonate, an important platform compound that is ranked in the top 30 value-added chemicals published by the U.S. Department of Energy [3]. S. cerevisiae was genetically modified to produce D-xylonate by expressing heterogeneous D-xylose dehydrogenase encoding genes $[4,5]$. However, the production rates were much lower than those observed with some bacteria [6], and the engineered S. cerevisiae showed poor performance on D-xylonate production at a low $\mathrm{pH}$. An unconventional yeast Pichia kudriavzevii was considered to be an excellent production organism for D-xylonate, with advantages over S. cerevisiae due to its remarkable tolerance towards D-xylonate, low $\mathrm{pH}$ stress and lignocellulosic inhibitors [7,8]. Moreover, 
P. kudriavzevii also showed a higher capacity for ethanol production from non-detoxified lignocelluosic biomass than S. cerevisiae $[9,10]$, making it a potential candidate host for improving the lignocellulosic-based bioeconomy.

Due to the competitive inhibition of D-xylose transport by D-glucose, it is difficult to produce ethanol and xylose derivatives simultaneously. Some integrated strategies are proposed to separately utilize D-xylose and D-glucose by different microorganisms. In previous studies, Gluconobacter oxydans and S. cerevisiae were employed to produce D-xylonate using xylose-rich hydrolysates from the pretreated biomass, and ethanol using enzymatic hydrolyzates from glucan residue, respectively [11,12]. Instead of two separate processes, a combination of these microorganisms enables the synthesis of two products in the same bioreactor, saving the time and energy consumption required for sterilization of the bioreactor and growth media, reducing time for the preparation of equipment, etc. Some efforts have been made regarding the sequential production of xylitol and ethanol from non-detoxified acid-pretreated corncob using single robust yeast strains [13,14]. In these studies, two-stage fermentation comprising aerobic xylitol production and simultaneous saccharification and micro-anaerobic ethanol fermentation were performed directly using acid-pretreated corncob without filtration, making the lignocellulosic ethanol industry more economical.

In this study, we constructed an engineering P. kudriavzevii strain for D-xylonate production without xylitol by replacing the D-xylose reductase gene with a D-xylose dehydrogenase gene using the URA3 pop-out system. The recombinant strain P. kudriavzevii $\mathrm{N}-\mathrm{X} / \mathrm{S} 1$ exhibited excellent $\mathrm{D}$-xylonate and ethanol productivity at low $\mathrm{pH}$ conditions using D-xylose and D-glucose medium, respectively. A two-stage fermentation strategy was then proposed for sequential production of D-xylonate and ethanol from non-detoxified acidpretreated corncob at low $\mathrm{pH}$. Our work offers an alternative approach to improve the economic viability of lignocellulose biorefinement.

\section{Materials and Methods}

\subsection{Strains and Medium}

P. kudriavzevii N-X (CCTCC M2017759) was isolated from Kazakh cheese and S. cerevisiae W13 was isolated from grape skin, and they were deposited in our lab at $-80^{\circ} \mathrm{C}$. The yeast strains were cultured in YPD medium $(20 \mathrm{~g} / \mathrm{L}$ D-glucose, $20 \mathrm{~g} / \mathrm{L}$ peptone, $10 \mathrm{~g} / \mathrm{L}$ yeast extract) for maintenance. Minimal medium (MM, 6.7 g/L yeast nitrogen base without amino acids, $20 \mathrm{~g} / \mathrm{L}$ D-glucose) was used for selecting yeast transformants. Minimal medium supplemented with $0.1 \mathrm{~g} / \mathrm{L}$ uracil and $1 \mathrm{~g} / \mathrm{L}$ 5-Fluoroorotic acid (5-FOA) was used for the selection of uracil auxotrophic mutant. Escherichia coli DH5 $\alpha$ was cultured in Luria-Bertani (LB) medium (10 g/L peptone, $5 \mathrm{~g} / \mathrm{L}$ yeast extract, $10 \mathrm{~g} / \mathrm{L} \mathrm{NaCl}$ ) for plasmid construction and propagation.

\subsection{Strain Construction}

For efficient genetic manipulation in P. kudriavzevii N-X, we constructed a uracil auxotrophic mutant using a previously reported method [15]. To construct a D-xylonate producing strain, the D-xylose reductase gene XYL1 was replaced with the codon-optimized D-xylose dehydrogenase gene $x y l B$ (Table S1) from Caulobacter crescentus using the URA3 pop-out system (Figure S1). In this case, the $x y l B$ gene was synthesized by Genewiz (Suzhou, China), and cloned under the TDH promoter. The URA3 pop-out system was then constructed in the plasmid pMD19T (Takara Bio, Dalian, China) using a ClonExpress ${ }^{\circledR}$ MultiS One Step Cloning Kit (Vazyme, Nanjing, China). The primers used in this study were listed in Table S2. The obtained plasmid was lined and introduced into the uracil auxotrophic mutant by the previous reported method [14]. The recombinant strain $P$. kudriavzevii $\mathrm{N}-\mathrm{X} / \mathrm{S} 1$ was obtained from the MM medium. 


\subsection{Ethanol and D-xylonate Fermentation in Flasks}

To evaluate the ethanol fermentation capacity under various environmental stresses, P. kudriavzevii $\mathrm{N}-\mathrm{X}$ was cultured in $250 \mathrm{~mL}$ flasks containing $100 \mathrm{~mL}$ YP medium supplemented with different concentrations of D-glucose. The initial $\mathrm{pH}$ of the culture medium was adjusted to $2.0-6.0$ using $\mathrm{HCl}$ before autoclaving, the temperature was set at $30-45^{\circ} \mathrm{C}$, and the rotation speed of the shaker was set at $100 \mathrm{rpm}$. S. cerevisiae W13 was used as a control for ethanol fermentation at different initial $\mathrm{pH}$ conditions and $30^{\circ} \mathrm{C}$.

For D-xylonate production, the recombinant $P$. kudriavzevii $\mathrm{N}-\mathrm{X} / \mathrm{S} 1$ was cultured in $250 \mathrm{~mL}$ flasks containing $50 \mathrm{~mL}$ YPD medium supplemented with $50 \mathrm{~g} / \mathrm{L}$ D-xylose at $37^{\circ} \mathrm{C}$. The rotation speed of the shaker was set at $250 \mathrm{rpm}$, and the initial $\mathrm{pH}$ of the medium was adjusted to 3.0 and 5.5, respectively. All the experiments were repeated in triplicate.

\subsection{Materials and Acid Pretreatment}

Corncobs used in this study were collected from a farm in Zhejiang province, China. After air drying to constant mass, the material was ground by a hammer mill and then filtered through a 10-mesh screen. The composition of raw material was determined as $30.8 \pm 0.51 \%$ xylan, $42.5 \pm 0.22 \%$ glucan and $14.5 \pm 0.35 \%$ lignin by the protocol from National Renewable Energy Laboratory (NERL) [16]. The cellulase CE1000 was obtained from Jiangsu Boli Bioproducts Co., Ltd. in China, and its activity (92.5 FPU/g) was determined following the procedure recommended by the NREL [17].

The acid pretreatment was performed in a stainless-steel reactor following the method described in a previous study [13]. Briefly, milled corncob was slurred at a solid-liquid ratio of $1: 3$ with $0.5 \%(w / w)$ sulphuric acid and $1.5 \%(w / w)$ phosphoric acid, and then autoclaved at $125^{\circ} \mathrm{C}$ for $1 \mathrm{~h}$. Since a high solid-liquid ratio might cause insufficient mass transfer [18], sterile water was added to the mixture to adjust the solid-liquid ratio of 1:8, after acid pretreatment. The $\mathrm{pH}$ of corncob slurry was adjusted to 4.0. To evaluate the combined effects of inhibitors on P. kudriavzevii N-X/S1 under $\mathrm{pH} 4.0$, the medium was prepared using the liquid fraction of lignocellulosic slurry supple-mented with $10 \mathrm{~g} / \mathrm{L}$ yeast extract, $20 \mathrm{~g} / \mathrm{L}$ peptone and D-glucose to $20 \mathrm{~g} / \mathrm{L}$, and then fil-trated through a $0.22 \mu \mathrm{m}$ membrane for sterilization.

\subsection{Two-Stage Fermentations}

The recombinant $P$. kudriavzevii $\mathrm{N}-\mathrm{X} / \mathrm{S} 1$ was cultured in a $500 \mathrm{~mL}$ flask containing $100 \mathrm{~mL}$ YPD medium for $16 \mathrm{~h}$ at $37^{\circ} \mathrm{C}$ and $250 \mathrm{rpm}$ for seed preparation. For two-stage fermentation with pure sugars, the seed culture was inoculated at $5 \%(v / v)$ into the $2 \mathrm{~L}$ YPD medium supplemented with $50 \mathrm{~g} / \mathrm{L}$ D-xylose at an initial $\mathrm{pH}$ of 5.5 in a $5 \mathrm{~L}$ bioreactor (BIOTECH-5BG, Bxbio, Shanghai, China). At the first stage, aerobic fermentation was performed at $40{ }^{\circ} \mathrm{C}$ with an agitation speed of $500 \mathrm{rpm}$ and an aeration rate of $1.5 \mathrm{vvm}$. After D-xylose was depleted, a glucose stock of $500 \mathrm{~g} / \mathrm{L}$ was fed into the culture at one time until the final concentration reached $150 \mathrm{~g} / \mathrm{L}$, then a shift to micro-anaerobic conditions was performed by controlling the aeration rate at $0.2 \mathrm{vvm}$ for ethanol production. The $\mathrm{pH}$ value was not controlled during the whole fermentation process.

For two-stage fermentation using non-detoxified corncob, $10 \mathrm{~g} / \mathrm{L}$ yeast extract and $20 \mathrm{~g} / \mathrm{L}$ peptone was added to the acid-pretreated corncob slurry, and D-glucose was added to $20 \mathrm{~g} / \mathrm{L}$ for cell growth at the first stage. After all of the D-xylose was converted to D-xylonate at 48 h, $20 \mathrm{FPU} / \mathrm{g}$ corncob was added and simultaneous saccharification and fermentation was performed in micro-anaerobic conditions (aeration rate at $0.2 \mathrm{vvm}$ and $40^{\circ} \mathrm{C}$ ). The $\mathrm{pH}$ was controlled at 4.0 using $5 \mathrm{M} \mathrm{NaOH}$.

\subsection{Analytical Methods}

For the determination of dried cell weight (DCW), $2 \mathrm{~mL}$ samples were collected in a pre-dried centrifuge tube, washed twice and then dried in a vacuum drying oven at $105^{\circ} \mathrm{C}$. Sugars, organic acids, furfural and 5-HMF were identified and quantified using a high-performance liquid chromatograph (HPLC; Hitachi, Tokyo, Japan) equipped with 
refractive index (RI) and UV detectors and an Aminex HPX-87H column (Bio-Rad, Hercules, CA, USA), following the method described in our precious study [8].

\section{Results}

\subsection{Ethanol Fermentation Capacity of P. kudriavzevii N-X}

P. kudriavzevii strains exhibited greater ethanol production capacity than conventional S. cerevisiae under some harsh conditions, such as high temperature, hyperosmotic stress and inhibitor stress $[10,19,20]$. The strain $P$. kudriavzevii $\mathrm{N}-\mathrm{X}$ reported in our previous study showed excellent low-pH stress tolerance, but its ethanol fermentation capacity has not been evaluated yet [21]. Herein, we firstly evaluated the capacity of $P$. kudriavzevii N-X for ethanol production under various conditions in flasks. P. kudriavzevii was reported to have high osmotolerance, tolerating up to $48 \%(w / v)$ D-glucose, but the ethanol productivity is usually affected under high D-glucose concentrations $[9,22,23]$. In this study, P. kudriavzevii $\mathrm{N}-\mathrm{X}$ showed a similar yield and productivity of ethanol in the presence of 100 and $150 \mathrm{~g} / \mathrm{L}$ D-glucose, but the ethanol fermentation capacities were significantly reduced when the initial D-glucose concentration was further increased to $200 \mathrm{~g} / \mathrm{L}$ (Table S3). P. kudriavzevii $\mathrm{N}-\mathrm{X}$ can ferment at high temperatures, but its ethanol production capacity at $45^{\circ} \mathrm{C}$ was not superior to that of some reported $P$. kudriavzevii strains $[19,23]$. The maximum ethanol yield $\left(94.3 \%\right.$ of theoretical yield) and productivity $(3.01 \mathrm{~g} / \mathrm{L} / \mathrm{h})$ were obtained at $40{ }^{\circ} \mathrm{C}$ (Table S4).

To explore the possibility of ethanol fermentation in low $\mathrm{pH}$ conditions, batch cultivations were performed under various initial $\mathrm{pH}$ conditions. The results showed that $P$. kudriavzevii $\mathrm{N}-\mathrm{X}$ maintained high ethanol production capacity in the initial $\mathrm{pH}$ range of $3.0-6.0$; it produced $67.1 \mathrm{~g} / \mathrm{L}$ ethanol at $87.7 \%$ of the theoretical yield and its productivity was $2.40 \mathrm{~g} /(\mathrm{L} \cdot \mathrm{h})$ at $\mathrm{pH} 3.0$, while $\mathrm{S}$. cerevisiae W13 produced only $44.6 \mathrm{~g} / \mathrm{L}$ ethanol at $58.3 \%$ of the theoretical yield and its productivity was $1.24 \mathrm{~g} /(\mathrm{L} \cdot \mathrm{h})($ Table 1$)$. Moreover, P. kudriavzevii N-X performed much better than S. cerevisiae W13 at lower $\mathrm{pH}$ levels, the yield of ethanol was decreased to $49.2 \%$ of the theoretical yield at $\mathrm{pH} 2.0$, while S. cerevisiae W13 did not grow at all. The decrease in the ethanol fermentation capacity of $P$. kudriavzevii $\mathrm{N}-\mathrm{X}$ under extreme acidic conditions may be due to the decreased count of viable cells and prolonged lag phase (data not shown). Additionally, P. kudriavzevii N-X grows as large aggregates at $\mathrm{pH}$ levels below 2.5, which affects nutrient transfer and oxygen diffusion, and so is not suited to low-pH fermentation [21].

Table 1. Ethanol production of Pichia kudriavzevii N-X and Saccharomyces cerevisiae W13 under different initial pH conditions.

\begin{tabular}{|c|c|c|c|c|c|c|c|c|}
\hline \multirow[b]{2}{*}{$\mathrm{pH}$} & \multicolumn{4}{|c|}{ P. kudriavzevii N-X } & \multicolumn{4}{|c|}{ S. cerevisiae W13 } \\
\hline & $\begin{array}{l}\text { Fermentation } \\
\text { Time (h) }\end{array}$ & $\begin{array}{l}\text { Ethanol } \\
\text { (g/L) }\end{array}$ & $\begin{array}{c}\% \text { of Theoretical } \\
\text { Yield }\end{array}$ & $\begin{array}{l}\text { Productivity } \\
\text { (g/L/h) }\end{array}$ & $\begin{array}{l}\text { Fermentation } \\
\text { Time (h) }\end{array}$ & $\begin{array}{l}\text { Ethanol } \\
(\mathrm{g} / \mathrm{L})\end{array}$ & $\begin{array}{c}\% \text { of Theoretical } \\
\text { Yield }\end{array}$ & $\begin{array}{l}\text { Productivity } \\
\text { (g/L/h) }\end{array}$ \\
\hline 2.0 & 48 & $37.6 \pm 2.8$ & $49.2 \pm 3.6$ & $0.78 \pm 0.06$ & - & - & - & - \\
\hline 2.5 & 32 & $52.7 \pm 2.0$ & $68.9 \pm 2.5$ & $1.65 \pm 0.06$ & 48 & $25.2 \pm 1.0$ & $33.0 \pm 2.4$ & $0.53 \pm 0.02$ \\
\hline 3.0 & 28 & $67.1 \pm 1.7$ & $87.7 \pm 2.2$ & $2.40 \pm 0.06$ & 36 & $44.6 \pm 1.9$ & $58.3 \pm 2.4$ & $1.24 \pm 0.06$ \\
\hline 4.0 & 24 & $70.5 \pm 2.0$ & $92.1 \pm 2.6$ & $2.94 \pm 0.08$ & 28 & $66.3 \pm 0.9$ & $86.7 \pm 1.2$ & $2.34 \pm 0.03$ \\
\hline 5.0 & 24 & $71.4 \pm 0.9$ & $93.3 \pm 1.1$ & $2.98 \pm 0.04$ & 24 & $67.3 \pm 1.1$ & $88.0 \pm 1.4$ & $2.80 \pm 0.05$ \\
\hline 6.0 & 24 & $68.2 \pm 2.7$ & $89.2 \pm 3.5$ & $2.84 \pm 0.11$ & 24 & $68.4 \pm 1.0$ & $89.4 \pm 1.3$ & $2.85 \pm 0.04$ \\
\hline
\end{tabular}

The experiments were repeated in triplicate. The data present the average \pm SD.

\subsection{Construction of a D-xylonate-Producing P. kudriavzevii}

$P$. kudriavzevii is an excellent host for D-xylonate production utilizing D-xylose because it has a high tolerance for and does not catabolize D-xylonate $[7,8]$. However, some $P$. kudriavzevii strains could also metabolize D-xylose for cell growth or convert xylose into xylitol, which might reduce the yield of D-xylonate from D-xylose. It was found that $P$. kudriavzevii strains exhibited different abilities to utilize xylose, although their genomes contain the three key enzymes required for D-xylose utilization [24]. Early taxonomic studies claimed that $P$. kudriavzevii could not assimilate and ferment D-xylose, but some strains were reported to be able to metabolize D-xylose for growth $[7,22,25]$. In a previous 
study, the yield of D-xylonate from recombinant $P$. kudriavzevii VTT-C-12903 reached up to 0.9-1.0 g/g D-xylose, but a certain proportion of D-xylose was still consumed for cellular growth and xylitol production [7]. In this study, we evaluated the D-xylose metabolic capacity of $P$. kudriavzevii $\mathrm{N}-\mathrm{X}$ before constructing the D-xylonate producing strain. It showed that $P$. kudriavzevii $\mathrm{N}-\mathrm{X}$ could not grow in the medium using D-xylose as a sole carbon source, but it converted D-xylose to xylitol at a yield of $0.4 \mathrm{~g} / \mathrm{g}$ in the presence of D-glucose as carbon source (Figure 1a). These results indicate that the xylose catabolic pathway of $P$. kudriavzevii $\mathrm{N}-\mathrm{X}$ is nonfunctional, but the gene encoding $\mathrm{D}$-xylose reductase is at least active. Hence, to produce D-xylonate and at the same time eliminate the production of xylitol, we replaced the two copies of D-xylose reductase gene XYL1 in the uracil auxotrophic mutant of $P$. kudriavzevii $\mathrm{N}-\mathrm{X}$ with the codon-optimized D-xylose dehydrogenase gene from Caulobacter crescentus using the URA3 pop-out system. A recombinant strain, P. kudriavzevii $\mathrm{N}-\mathrm{X} / \mathrm{S} 1$, was obtained from the selective medium and confirmed by PCR (data not shown).

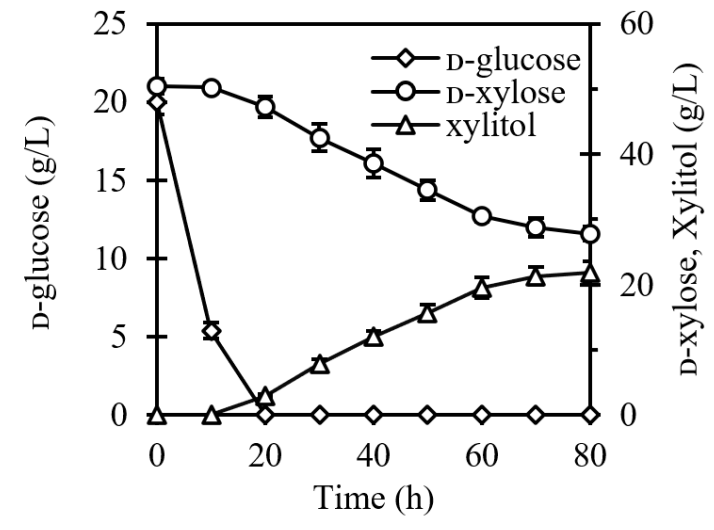

(a)

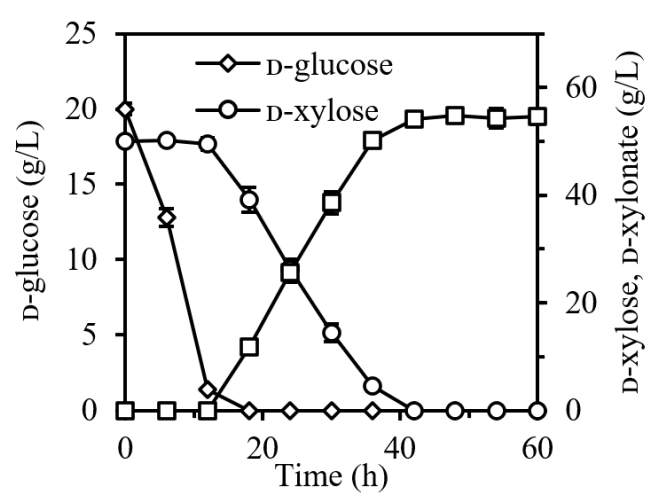

(b)

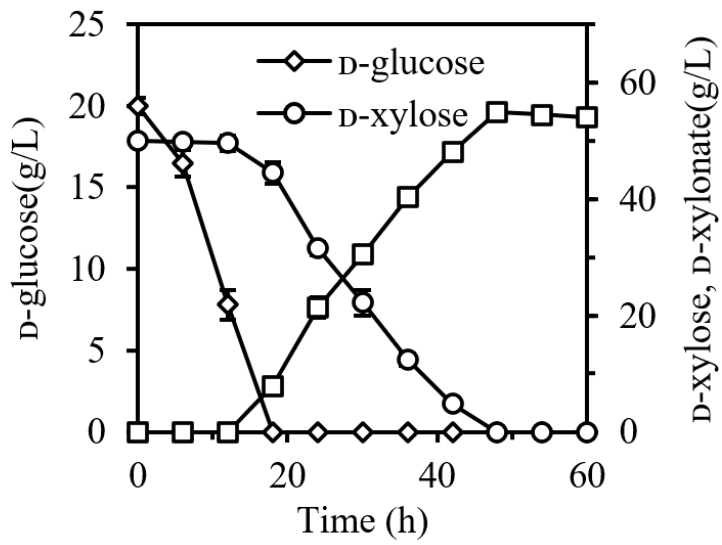

(c)

Figure 1. Time course of xylitol and D-xylonate production in the YPD medium containing $50 \mathrm{~g} / \mathrm{L}$ D-xylose. (a) Xylitol production of P. kudriavzevii N-X. D-xylonate production of P. kudriavzevii N-X/S1 at initial pH 5.5 (b) and pH 3.0 (c), respectively. Error bars represent \pm SD.

Batch fermentation was then performed under aerobic conditions in flasks containing YPD medium supplemented with $50 \mathrm{~g} / \mathrm{L}$ D-xylose. As shown in Figure 1b, the recombinant strain P. kudriavzevii N-X/S1 produced $54.8 \mathrm{~g} / \mathrm{L}$ D-xylonate within $40 \mathrm{~h}$ at a yield of $1.1 \mathrm{~g} / \mathrm{g}$ and a rate of $1.37 \mathrm{~g} \mathrm{~L}^{-1} \mathrm{~h}^{-1}$. The yield was higher than that of VTT-C-12903 under the same conditions, probably due to the absence of native xylose catabolism and the blocking of the conversion of D-xylose to xylitol. Moreover, the recombinant strain converted all the D-xylose to D-xylonate at a rate of $1.13 \mathrm{~g} \mathrm{~L}^{-1} \mathrm{~h}^{-1}$ at $\mathrm{pH} 3.0$ (Figure 1c), showing good potential in low-pH D-xylonate production. 


\subsection{Sequential Production of D-xylonate and Ethanol without $\mathrm{pH}$ Control by a Two-Stage Strategy}

The above results showed that recombinant $P$. kudriavzevii can efficiently produce ethanol and D-xylonate at low $\mathrm{pH}$ conditions, demonstrating its great potential for biotechnological conversion using lignocellulosic biomass rich in D-glucose and D-xylose. However, simultaneous fermentation of D-glucose and D-xylose cannot be realized because the presence of D-glucose strongly inhibits D-xylose transport [26]. It was reported that the two-stage fermentation strategy removed the glucose effect and enabled sequential consumption of D-xylose and D-glucose for the production of ethanol or co-production of ethanol and xylitol $[13,27,28]$. Herein, we investigated the continuous production of D-xylonate and ethanol by P. kudriavzevii N-X/S1 using pure D-xylose and D-glucose via a two-stage and fed-batch fermentation. In the first stage, P. kudriavzevii $\mathrm{N}-\mathrm{X} / \mathrm{S} 1$ was cultured in YPD medium containing $50 \mathrm{~g} / \mathrm{L}$ D-xylose under aerobic conditions, resulting in high biomass yield and an accumulation of D-xylonate. After D-xylose depletion, a shift to micro-anaerobic ethanol fermentation was performed, with $150 \mathrm{~g} / \mathrm{L}$ D-glucose being fed into the culture. As shown in Figure 2, 55.3 g/L D-xylonate was produced with a yield of $1.10 \mathrm{~g} / \mathrm{g}$ D-xylose in $42 \mathrm{~h}$ aerobic cultivation. The $\mathrm{pH}$ value of broth was 3.10 at the end of the first stage and it was not adjusted during the subsequent ethanol fermentation, since $P$. kudriavzevii N-X/S1 maintained a high ethanol fermentation capacity at a $\mathrm{pH}$ value around 3.0. In the second stage, ethanol was produced during $42-60 \mathrm{~h}$, and the yield and productivity reached $89.2 \%$ of theoretical yield and a rate of $2.84 \mathrm{~g} /(\mathrm{L} \cdot \mathrm{h})$, respectively. Importantly, the D-xylonate accumulating in the broth was not utilized any more during the whole fermentation process, as reported in a previous study [7]. In this case, by regulating the aerobic and micro-anaerobic conditions, D-xylose and D-glucose consumption was separated into two stages, avoiding the competitive inhibition of sugar transport. Fermentation without $\mathrm{pH}$ control reduces the cost of the base needed for acid neutralization, minimizes the risk of contamination and simplifies downstream engineering [29]. Moreover, D-xylonate and ethanol can be easily separated by distillation in the downstream processing because of their different boiling points. These results indicated that the sequential production of D-xylonate and ethanol in a single bioreactor can be achieved via a two-stage strategy.

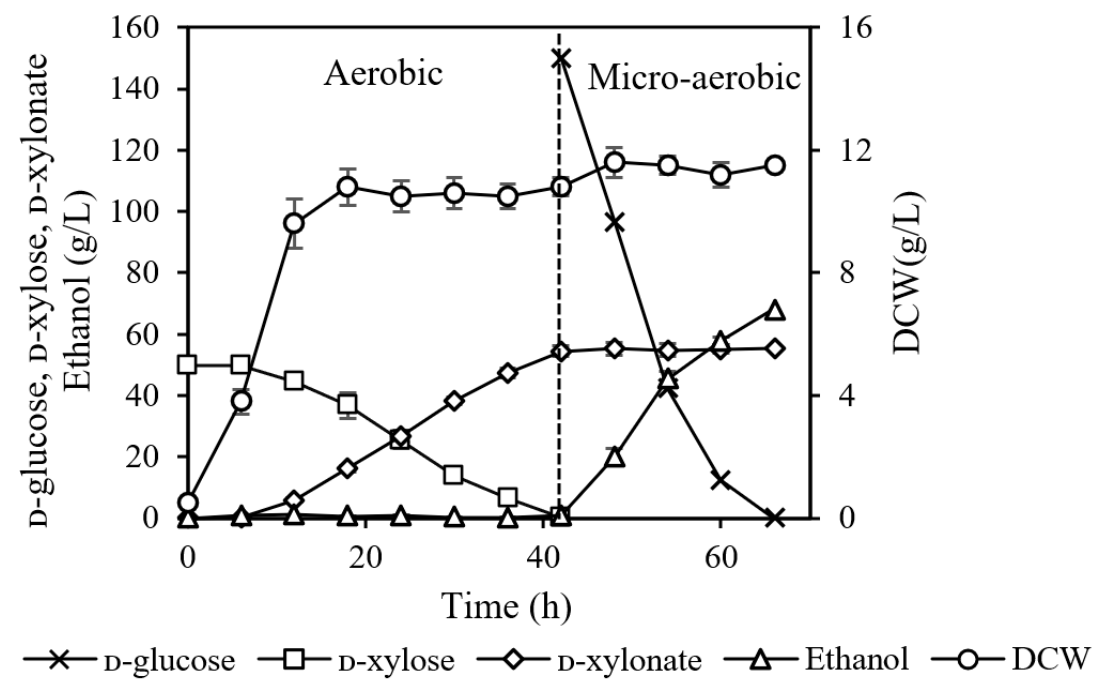

Figure 2. Sequential production of D-xylonate and ethanol from pure D-xylose and D-glucose medium by a two-stage fermentation.

\subsection{Sequential Production of D-xylonate and Ethanol Using Non-Detoxified Corncob}

P. kudriavzevii strains exhibited multi-tolerance to inhibitors and have been used in ethanol production from non-detoxified lignocellulosic biomass $[10,19,22,30]$. Nevertheless, D-xylose in the lignocellulosic hydrolysates is usually retained because it cannot be 
efficiently consumed by P. kudriavzevii, resulting in reduced economic feasibility. Herein, aerobic D-xylonate and micro-anaerobic ethanol fermentation from non-detoxified corncob were integrated using P. kudriavzevii N-X/S1 via a two-stage strategy. In this case, the liquid fraction of acid-pretreated corncob without detoxification contained $30.4 \mathrm{~g} / \mathrm{L}$ D-xylose, and $2.80 \mathrm{~g} / \mathrm{L}$ D-glucose, $0.55 \mathrm{~g} / \mathrm{L}$ furfural, $0.38 \mathrm{~g} / \mathrm{L} 5-\mathrm{HMF}$ and $1.20 \mathrm{~g} / \mathrm{L}$ acetic acid. For low-pH fermentation, the $\mathrm{pH}$ value of the culture would be controlled at 4.0, since the commercial acidic cellulases usually have low activity at a lower $\mathrm{pH}$ [31]. Previous studies suggested that $P$. kudriavzevii strains were tolerant of the inhibitors at concentrations much higher than those in our acid-pretreated corncob $[19,30]$. To evaluate the combined effects of inhibitors and low $\mathrm{pH}$ on P. kudriavzevii $\mathrm{N}-\mathrm{X} / \mathrm{S} 1$, we compared the cell growth and $D$-xylonate production in flasks using the liquid fraction of non-detoxified acid-pretreated corncob hydrolysate and pure D-xylose medium. D-glucose was supplemented with an additional $20 \mathrm{~g} / \mathrm{L}$ because the amount in the acid-pretreated hydrolysate was not enough to support cell growth. As shown in Figure 3, lower cell growth and a prolonged lag phase were observed with non-detoxified acid-pretreated hydrolysate as substrate. The accumulation of D-xylonate was slower than when using pure D-xylose as substrate, but the yield was maintained at $1.10 \mathrm{~g} / \mathrm{g}$. These results suggested that the combined inhibitors in corncob hydrolysate had limited the repression effect on P. kudriavzevii N-X/S1 at $\mathrm{pH}$ 4.0.

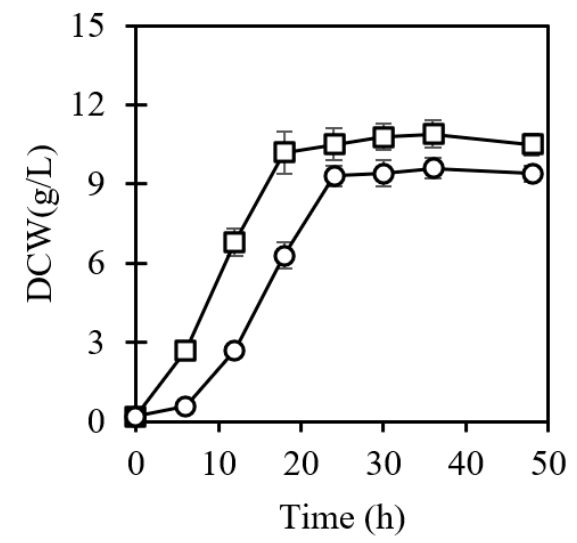

(a)

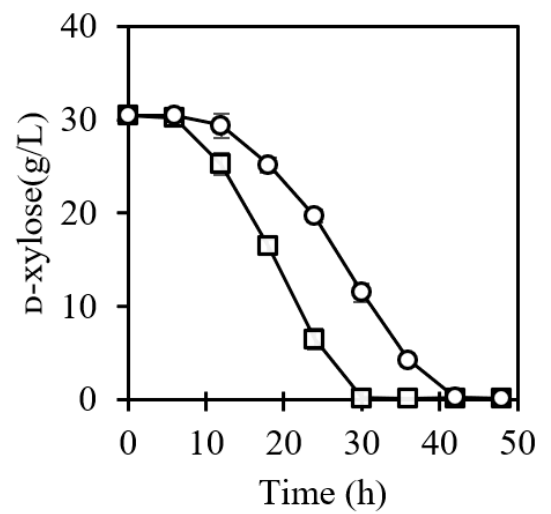

(c)

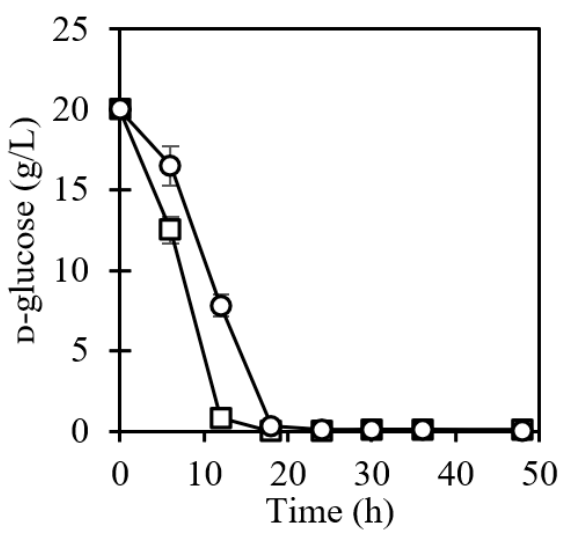

(b)

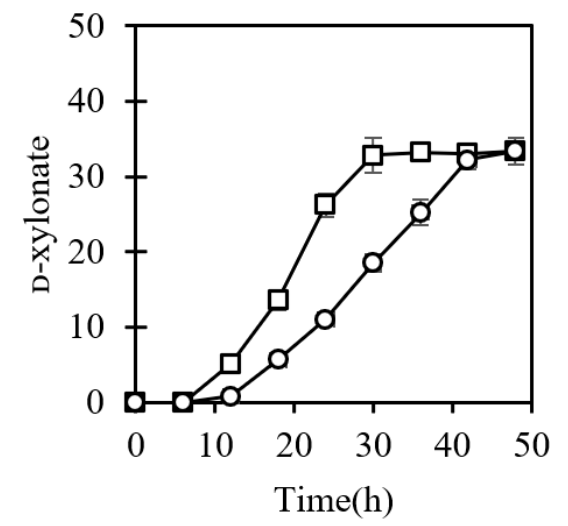

(d)

Figure 3. Effect of combined inhibitors on cell growth (a), D-glucose (b) and D-xylose consumption (c) and D-xylonate (d) production of P. kudriavzevii N-X/S1 at $\mathrm{pH} 4.0$. The cells were cultured in the medium prepared by the liquid fraction of acid-pretreated corncob without detoxification (open circles) or YPD medium supplemented with $30.4 \mathrm{~g} / \mathrm{L}$ D-xylose (open squares).

The two-stage fermentation was carried out at $40{ }^{\circ} \mathrm{C}$, which is the optimum temperature for ethanol fermentation of $P$. kudriavzevii $\mathrm{N}-\mathrm{X} / \mathrm{S} 1$, and the same temperature was maintained for saccharification. D-glucose concentration was not shown because it was 
consumed immediately during the saccharification process. As shown in Figure 4, D-xylose present in the acid-pretreated corncob slurry was totally converted to $33.5 \mathrm{~g} / \mathrm{L}$ D-xylonate at $\mathrm{pH} 4.0$ after $48 \mathrm{~h}$ aerobic incubation. In the case of solids loading, the depletion of D-xylose was delayed, probably due to insufficient mass transfer. After acidic cellulase application, about $80.2 \%$ of glucan was hydrolyzed to monomeric D-glucose and $20.8 \mathrm{~g} / \mathrm{L}$ ethanol was produced by simultaneous saccharification and micro-anaerobic fermentation within another $48 \mathrm{~h}$, at $84.3 \%$ of the theoretical yield. The mass balance of the two-stage fermentation by corncob showed that $26.8 \mathrm{~g}$ D-xylonate and $16.6 \mathrm{~g}$ ethanol were produced from $100 \mathrm{~g}$ corncob. This is the first study reporting the sequential production of D-xylonate and ethanol from non-detoxified lignocellulosic biomass at a low $\mathrm{pH}$ using a single microorganism. In previous studies, S. cerevisiae and G. oxydans were employed for aerobic D-xylonate and micro-anaerobic ethanol production from lignocellulosic biomass by two independent operations [11,12]. By contrast, the sequential production of D-xylonate and ethanol using $P$. kudriavzevii in the same container simplifies manufacturing, minimizes contamination and reduces wastewater generation. Limited by the activity of commercial cellulase, this two-stage fermentation is not feasible for operating under lower $\mathrm{pH}$ conditions. Nonetheless, the cost of $\mathrm{pH}$ titration is still effectively controlled in this study.

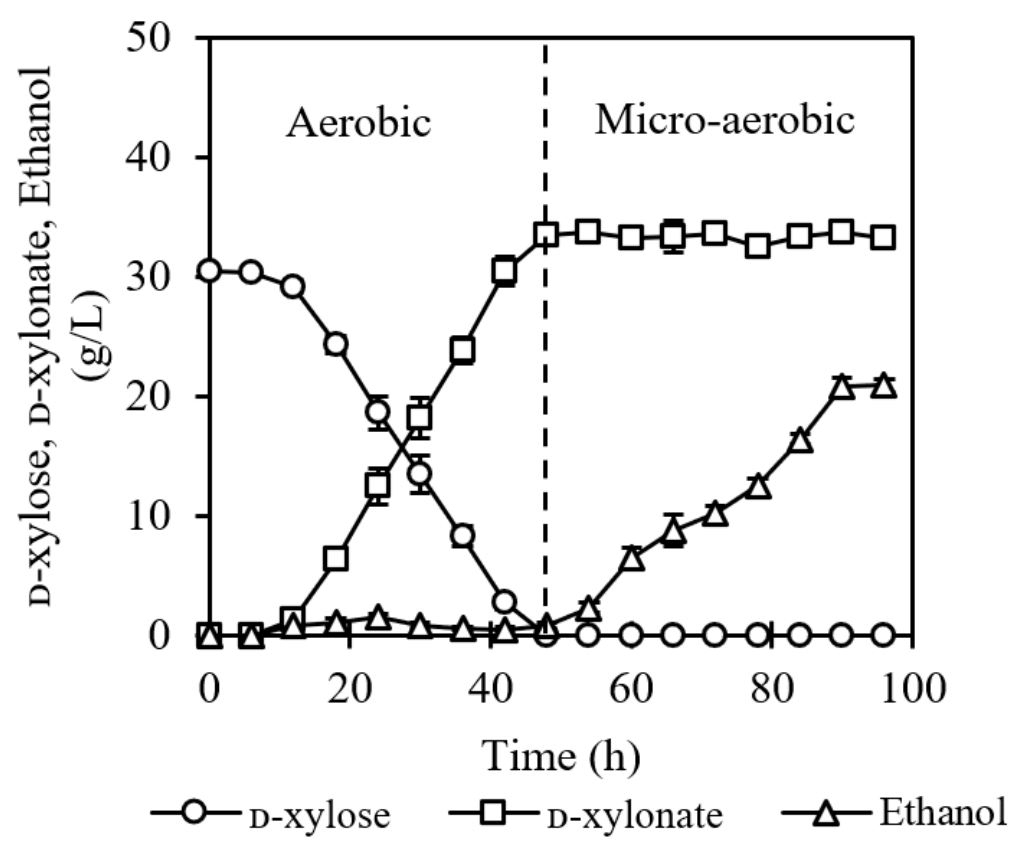

Figure 4. Sequential production of D-xylonate and ethanol from non-detoxified acid-pretreated corncob by a two-stage fermentation strategy.

\section{Conclusions}

In this study, a recombinant strain, P. kudriavzevii $\mathrm{N}-\mathrm{X} / \mathrm{S} 1$, was constructed to produce D-xylonate at a high yield and productivity without xylitol production. This strain also showed high tolerance of elevated temperatures, low $\mathrm{pH}$ conditions and lignocellulosic inhibitor stresses, and demonstrated high efficiency of ethanol productivity at elevated temperatures and in low $\mathrm{pH}$ conditions. Aerobic D-xylonate production and micro-anaerobic ethanol fermentation can be integrated in the same bioreactor using this single microorganism via a two-stage strategy. Furthermore, D-xylonate and ethanol were sequentially produced from whole slurry non-detoxified corncob at $\mathrm{pH} 4.0-$ a result which shows great potential for industrial applications. 
Supplementary Materials: The following are available online at https: / www.mdpi.com/article/ 10.3390/jof7121038/s1, Figure S1: Schematic diagram of expression $x y l B$ at the XYL1 locus using the URA3 pop-out system, Table S1: Sequence of NAD+-dependent xylose dehydrogenase gene $x y l B$, Table S2: Primers used in this study, Table S3: Ethanol production of $P$. kudriavzevii N-X in YP medium containing different concentrations of D-glucose by shaking flasks at $100 \mathrm{rpm}$ and $37^{\circ} \mathrm{C}$, Table S4: Ethanol production of P. kudriavzevii N-X in YP medium containing $150 \mathrm{~g} / \mathrm{L}$ D-glucose glucose by shaking flasks at $100 \mathrm{rpm}$ and different temperatures.

Author Contributions: Conceptualization, H.J. and K.X.; software, D.S.; formal analysis, H.J.; investigation, K.X.; data curation, X.D.; writing-original draft preparation, H.J.; writing-review and editing, H.J., D.S. and X.D.; visualization, X.D.; supervision, L.J.; project administration, L.J.; funding acquisition, H.J. and K.X. All authors have read and agreed to the published version of the manuscript.

Funding: This work was supported by the National Natural Science Foundation of China (81802251), the Natural Science Foundation of Zhejiang Province (LQ20C200015, LQ18H150003) and Basic scientific research projects of Wenzhou (G20180020).

Institutional Review Board Statement: Not applicable.

Informed Consent Statement: Not applicable.

Data Availability Statement: Not applicable.

Conflicts of Interest: The authors declare no conflict of interest.

\section{References}

1. Moysés, D.N.; Reis, V.C.B.; Almeida, J.R.M.d.; Moraes, L.M.P.d.; Torres, F.A.G. Xylose Fermentation by Saccharomyces cerevisiae: Challenges and Prospects. Int. J. Mol. Sci. 2016, 17, 207. [CrossRef] [PubMed]

2. Budzianowski, W.M. High-value low-volume bioproducts coupled to bioenergies with potential to enhance business development of sustainable biorefineries. Renew. Sust. Energ. Rev. 2017, 70, 793-804. [CrossRef]

3. Cao, Y.; Xian, M.; Zou, H.; Zhang, H. Metabolic engineering of Escherichia coli for the production of xylonate. PLoS ONE 2013, 8, e67305. [CrossRef]

4. Toivari, M.H.; Ruohonen, L.; Richard, P.; Penttila, M.; Wiebe, M.G. Saccharomyces cerevisiae engineered to produce D-xylonate. Appl. Microbiol. Biotechnol. 2010, 88, 751-760. [CrossRef]

5. Toivari, M.; Nygard, Y.; Kumpula, E.P.; Vehkomaki, M.L.; Bencina, M.; Valkonen, M.; Maaheimo, H.; Andberg, M.; Koivula, A.; Ruohonen, L.; et al. Metabolic engineering of Saccharomyces cerevisiae for bioconversion of D-xylose to D-xylonate. Metab. Eng. 2012, 14, 427-436. [CrossRef] [PubMed]

6. Banares, A.B.; Nisola, G.M.; Valdehuesa, K.N.G.; Lee, W.K.; Chung, W.J. Understanding D-xylonic acid accumulation: A cornerstone for better metabolic engineering approaches. Appl. Microbiol. Biotechnol. 2021, 105, 5309-5324. [CrossRef]

7. Toivari, M.; Vehkomaki, M.L.; Nygard, Y.; Penttila, M.; Ruohonen, L.; Wiebe, M.G. Low pH D-xylonate production with Pichia kudriavzevii. Bioresour. Technol. 2013, 133, 555-562. [CrossRef]

8. Ji, H.; Lu, X.; Zong, H.; Zhuge, B. A synthetic hybrid promoter for D-xylonate production at low $\mathrm{pH}$ in the tolerant yeast Candida glycerinogenes. Bioengineered 2017, 8, 700-706. [CrossRef]

9. Mukherjee, V.; Radecka, D.; Aerts, G.; Verstrepen, K.J.; Lievens, B.; Thevelein, J.M. Phenotypic landscape of non-conventional yeast species for different stress tolerance traits desirable in bioethanol fermentation. Biotechnol. Biofuels 2017, 10, 216. [CrossRef] [PubMed]

10. Yuan, S.F.; Guo, G.L.; Hwang, W.S. Ethanol production from dilute-acid steam exploded lignocellulosic feedstocks using an isolated multistress-tolerant Pichia kudriavzevii strain. Microb. Biotechnol. 2017, 10, 1581-1590. [CrossRef] [PubMed]

11. Zhu, J.; Rong, Y.; Yang, J.; Zhou, X.; Xu, Y.; Zhang, L.; Chen, J.; Yong, Q.; Yu, S. Integrated production of xylonic acid and bioethanol from acid-catalyzed steam-exploded corn stover. Appl. Biochem. Biotechnol. 2015, 176, 1370-1381. [CrossRef]

12. Huang, C.; Ragauskas, A.J.; Wu, X.; Huang, Y.; Zhou, X.; He, J.; Huang, C.; Lai, C.; Li, X.; Yong, Q. Co-production of bio-ethanol, xylonic acid and slow-release nitrogen fertilizer from low-cost straw pulping solid residue. Bioresour. Technol. 2018, 250, 365-373. [CrossRef] [PubMed]

13. Du, C.; Li, Y.; Zong, H.; Yuan, T.; Yuan, W.; Jiang, Y. Production of bioethanol and xylitol from non-detoxified corn cob via a two-stage fermentation strategy. Bioresour. Technol. 2020, 310, 123427. [CrossRef]

14. Cheng, K.; Wu, J.; Lin, Z.; Zhang, J. Aerobic and sequential anaerobic fermentation to produce xylitol and ethanol using non-detoxified acid pretreated corncob. Biotechnol. Biofuels 2014, 23, 166. [CrossRef] [PubMed]

15. Xiao, H.; Shao, Z.; Jiang, Y.; Dole, S.; Zhao, H. Exploiting Issatchenkia orientalis SD108 for succinic acid production. Microb. Cell Fact. 2014, 13, 121. [CrossRef]

16. Sluiter, A.; Hames, B.; Ruiz, R.; Scarlata, C.; Sluiter, J.; Templeton, D.; Crocker, D. Determination of Structural Carbohydrates and Lignin in Biomass; Technical Report NREL/TP-510-42618; National Renewable Energy Laboratory: Golden, CO, USA, 2010. 
17. Adney, B.; Baker, J. Measurement of Cellulase Activities; Technical Report NREL/TP-510-42628; National Renewable Energy Laboratory: Golden, CO, USA, 2008.

18. Pino, M.S.; Rodríguez-Jasso, R.M.; Michelin, M.; Flores-Gallegos, A.C.; Morales-Rodriguez, R.; Teixeira, J.A.; Ruiz, H.A. Bioreactor design for enzymatic hydrolysis of biomass under the biorefinery concept. Chem. Eng. J. 2018, 347, 119-136. [CrossRef]

19. Seong, Y.J.; Lee, H.J.; Lee, J.E.; Kim, S.; Lee, D.Y.; Kim, K.H.; Park, Y.C. Physiological and metabolomic analysis of Issatchenkia orientalis MTY1 with multiple tolerance for cellulosic bioethanol production. Biotechnol. J. 2017, 12, 1700110. [CrossRef] [PubMed]

20. Oberoi, H.S.; Babbar, N.; Sandhu, S.K.; Dhaliwal, S.S.; Kaur, U.; Chadha, B.S.; Bhargav, V.K. Ethanol production from alkali-treated rice straw via simultaneous saccharification and fermentation using newly isolated thermotolerant Pichia kudriavzevii HOP-1. J. Ind. Microbiol. Biotechnol. 2012, 39, 557-566. [CrossRef]

21. Ji, H.; Xu, K.; Dong, X.; Sun, D.; Peng, R.; Lin, S.; Zhang, K.; Jin, L. Transcriptional profiling reveals molecular basis and the role of arginine in response to low-pH stress in Pichia kudriavzevii. J. Biosci. Bioeng. 2020, 130, 588-595. [CrossRef] [PubMed]

22. Ndubuisi, I.A.; Qin, Q.; Liao, G.; Wang, B.; Moneke, A.N.; Ogbonna, J.C.; Jin, C.; Fang, W. Effects of various inhibitory substances and immobilization on ethanol production efficiency of a thermotolerant Pichia kudriavzevii. Biotechnol. Biofuels 2020, $13,91$. [CrossRef]

23. Yuangsaard, N.; Yongmanitchai, W.; Yamada, M.; Limtong, S. Selection and characterization of a newly isolated thermotolerant Pichia kudriavzevii strain for ethanol production at high temperature from cassava starch hydrolysate. Antonie Leeuwenhoek 2013, 103, 577-588. [CrossRef]

24. Chan, G.F.; Gan, H.M.; Ling, H.L.; Rashid, N.A. Genome sequence of Pichia kudriavzevii M12, a potential producer of bioethanol and phytase. Eukaryot. Cell 2012, 11, 1300-1301. [CrossRef]

25. Koutinas, M.; Patsalou, M.; Stavrinou, S.; Vyrides, I. High temperature alcoholic fermentation of orange peel by the newly isolated thermotolerant Pichia kudriavzevii KVMP10. Lett. Appl. Microbiol. 2016, 62, 75-83. [CrossRef] [PubMed]

26. Farwick, A.; Bruder, S.; Schadeweg, V.; Oreb, M.; Boles, E. Engineering of yeast hexose transporters to transport D-xylose without inhibition by D-glucose. Proc. Natl. Acad. Sci. USA 2014, 111, 5159-5164. [CrossRef]

27. Jin, M.; Lau, M.W.; Balan, V.; Dale, B.E. Two-step SSCF to convert AFEX-treated switchgrass to ethanol using commercial enzymes and Saccharomyces cerevisiae 424A (LNH-ST). Bioresour. Technol. 2010, 101, 8171-8178. [CrossRef] [PubMed]

28. Li, W.-C.; Li, X.; Zhu, J.-Q.; Qin, L.; Li, B.-Z.; Yuan, Y.-J. Improving xylose utilization and ethanol production from dry dilute acid pretreated corn stover by two-step and fed-batch fermentation. Energy 2018, 157, 877-885. [CrossRef]

29. Chen, Y.; Nielsen, J. Biobased organic acids production by metabolically engineered microorganisms. Curr. Opin. Biotechnol. 2016, 37, 165-172. [CrossRef] [PubMed]

30. Kwon, Y.J.; Ma, A.Z.; Li, Q.; Wang, F.; Zhuang, G.Q.; Liu, C.Z. Effect of lignocellulosic inhibitory compounds on growth and ethanol fermentation of newly-isolated thermotolerant Issatchenkia orientalis. Bioresour. Technol. 2011, 102, 8099-8104. [CrossRef]

31. Payne, C.M.; Knott, B.C.; Mayes, H.B.; Hansson, H.; Himmel, M.E.; Sandgren, M.; Ståhlberg, J.; Beckham, G.T. Fungal Cellulases. Chem. Rev. 2015, 115, 1308-1448. [CrossRef] [PubMed] 